\title{
Observational learning vs shaping: A replication'
}

ROBERT W. POWELL

UNIVERSITY OF SOUTH FLORIDA

Shaping and observation learning were compared as methods for training albino rats to press a lever for milk reinforcement. The shaped group learned in fewer trials with the difference being significant at the .02 level. The observational group showed much greater variability in the acquisition of the response.

In a recent study Corson (1967) compared two methods for training rats to press a lever. These were shaping and observation learning. The shaping procedure, or method of successive approximation, is well-known and has been described many times (Skinner, 1951; Blough, 1964). Observation learning consists of giving a naive $S$ the opportunity to observe a trained $S$ perform the desired response. Corson found that the mean and median number of test sessions to reach criterion were significantly less for the observation group than the shaped group. The observation group did show greater variability, however.

Many studies have shown that observational or imitative learning develops and is maintained by the reinforcement contingencies which obtain (Bandura, 1965; Clark, 1965; Stimbert \& Schaffer, 1966). It would be expected, therefore, that shaping would be the more efficacious procedure in training an animal to perform a particular response as compared to observation. In shaping, intermediate stages in the development of a response are reinforced as well as the final performance; whereas in observation only the final performance is reinforced.

The present study was undertaken as a further comparison of observational learning and shaping. Method

The Ss in this experiment were 25 naive albino rats weighing from $225-300 \mathrm{~g}$. The apparatus was a standard Ralph Gerbrands operant conditioning chamber with a single lever. Borden's sweetened condensed milk diluted by an equal volume of water was used as the reinforcer. This was made available to the animal on a CRF schedule for lever pressing. Three deprivation conditions were employed, with Ss being run at either $70 \%, 80 \%$, or $90 \%$ of their ad lib weight. All Ss were approximately $23 \mathrm{~h}$ food deprived at the start of each session. The Ss had free access to water in their home cages throughout the experiment.

In the observation condition, the naive $S$ was placed in the experimental chamber with a trained model of the same sex for $15 \mathrm{~min}$. All models had previously met a criterion of 75 responses in $15 \mathrm{~min}$ and were maintained at $80 \%$ of their ad lib weight. The same models and naive Ss were always paired. After the observation period, the naive $S$ was left alone in the experimental chamber for $15 \mathrm{~min}$. This constituted the test period. The criterion for final performance was 50 or more responses during the test period.

In the shaping procedure the animals also had $15 \mathrm{~min}$ training and a $15 \mathrm{~min}$ test period in each session. They were first dipper trained and were then differentially reinforced for successive approximations to the desired response. The final criterion was the same as for the observation group.

One experimental session per day was run for both groups. If the naive $\mathrm{S}$ began to respond reliably under either training procedure, the test period was initiated at that point, rather than waiting until the training period had elapsed.

\section{Results and Discussion}

The number of training sessions to criterion is presented for each group in Table 1. The mean and median numbers of test sessions for the observational group was 9.6 and 6.0 respectively. The mean and median numbers of sessions for the shaped Ss were 4.1 and 3.5 respectively. An analysis of variance yielded an $F$ value significant beyond the .02 level. These results clearly indicate that shaping is a more effective procedure than observation for training rats to perform an instrumental response.

An inspection of the data suggests that the level of deprivation did not have a significant effect upon acquisition of the response in this experiment.

One of the rats in the imitation group had failed to acquire the response over 25 training sessions. This animal was then shaped and met the response criterion after three $15 \mathrm{~min}$ shaping sessions. This further demonstrates the effectiveness of shaping.

Table 1. Number of Test Sessions to Criterion

\begin{tabular}{ccccc} 
& \multicolumn{2}{c}{ Observational } & \multicolumn{2}{c}{ Shaped } \\
\hline & Ss No. & Sessions & Ss No. & Sessions \\
$70 \%$ & 1 & 25 & 12 & 3 \\
& 2 & 12 & 13 & 4 \\
& & & 14 & 3 \\
\hline & 3 & 14 & 15 & 6 \\
& 4 & 15 & 16 & 4 \\
$80 \%$ & 5 & 5 & 17 & 3 \\
& 6 & 5 & 18 & 3 \\
& & & 19 & 2 \\
& & & 20 & 6 \\
\hline & 7 & 6 & 21 & 5 \\
& & & 22 & 8 \\
$90 \%$ & 9 & 3 & 23 & 3 \\
& 10 & 1 & 24 & 3 \\
& 11 & 3 & 25 & 4 \\
\hline
\end{tabular}




\section{References}

BANDURA, A. Influence of model's reinforcement contingencies on the acquisition of imitative responses. J. Pers. Soc. Psychol., 1965, 1. 589-595.

BLOUGH, D. S., \& BLOUGH, P. M. Experiments in psychology. New York: Holt, Rinehart, \& Winston, 1964, pp. 44-47.

CLARK, B. S. The acquisition of peer imitation in children. Psychon. Sci., 2, 147-148.

CORSON, J. A. Observational learning of a lever pressing response.
Psychon. Sci., 1967, 7, 197-198.

SKINNER, B. F. How to teach animals. Scient. American, 1951, 185, 26-29.

STIMBERT, V. E., SCHAEFFER, R. W., \& GRIMSLEY, D. L. Acquisition of an imitative response in rats. Psychon. Sci., 1966, 5, 339-340.

Note

1. This research was supported in part by a grant from the University of South Florida Research Council. 